\title{
UTILIZAÇÃO DE TÉCNICAS DE MINERAÇÃO DE DADOS E ESTATÍSTICA PARA MELHORIA DA GESTÃO DO PROCESSO DE AVALIAÇÃO DE ATORES EM EDUCAÇÃO SEMIPRESENCIAL
}

\author{
FORTALEZA/CE JULHO/2018
}

\author{
Rafael Augusto Ferreira do Carmo - UFC - carmorafael@virtual.ufc.br \\ Elifrânio Alves Cruz - UFC - elifranio@virtual.ufc.br \\ João Guilherme Pereira de Miranda - LME/UFC - joao.guilherme@Ime.ufc.br \\ Antonia Izabella Sombra de Santiago - LME/UFC - izabellasombra@Ime.ufc.br \\ Gabriel Antoine Louis Paillard - UFC - gabriel@virtual.ufc.br \\ Robson Carlos Loureiro - UFC - robson@virtual.ufc.br \\ Luciana de Lima - UFC - luciana@virtual.ufc.br
}

Tipo: Investigação Científica (IC)

Natureza: Descrição de Projeto em Andamento

Categoria: Métodos e Tecnologias

Setor Educacional: EDUCAÇÃO SUPERIOR

\begin{abstract}
RESUMO
Este artigo apresenta o desenho, o desenvolvimento e resultados parciais de ações com enfoque em auxiliar o processo de gestão e avaliação de atores em um sistema de ensino semipresencial em execução. Tais ações são fruto da necessidade pedagógica de avaliação destes atores e da existência de restrições de pessoal e orçamentárias que fazem com que este processo não ocorra de forma plena. Técnicas de Computação e Estatística são apresentadas e discutidas dentro do contexto pedagógico que é foco do trabalho e os resultados parciais da utilização destes elementos são introduzidos e sua possível integração no ambiente de ensino-aprendizagem, bem como as implicações desta introdução são estudados. Os resultados e as discussões apresentadas indicam que é interessante a continuidade do estudo bem como a possibilidade de sucesso das ferramentas no ambiente de ensino-aprendizagem se mostram grandes.
\end{abstract}

Palavras-chave: Mineração de Dados, Fatoração de Matrizes, Redes Neurais, Estatística, Avaliação, Educação Semipresencial, UAB, Universidade Aberta do Brasil 
INTRODUÇÃOA Universidade Federal do Ceará (UFC), na modalidade de ensino de graduação à distância, gerenciada pelo Instituto UFC Virtual, oferta cursos semipresenciais em parceria com os governos do Estado e dos municípios, através do projeto nacional Universidade Aberta do Brasil (UAB), que visa à expansão do ensino superior a dista?ncia para regiões onde não há acesso hábil a cursos superiores na modalidade presencial. Para este propósito o Instituto UFC Virtual foi organizado administrativamente de forma a atender, além das demandas vinculadas às unidades acadêmicas tradicionais, às demandas vinculadas ao Ensino a Distância que estão sob sua responsabilidade. Um dos setores criados foi o setor de avaliação (SAV) que é responsável pelo planejamento, acompanhamento, avaliação e relato de atividades envolvendo a identificação de insuficiências e potencialidades do sistema, objetivando orientar mudanças e melhorias na qualidade de seu funcionamento. Para este fim, deve existir uma forma de acompanhamento das interações entre os docentes (tutores) e 0 corpo discente que compõem as turmas dos cursos semipresenciais ofertados no nosso ambiente virtual de aprendizagem (AVA), denominado SOLAR. As referidas interações acontecem nos fóruns vinculados às disciplinas do curso. De acordo com Rossato et al (2013) e Santos e Maciel (2014), a ferramenta mais comumente utilizada em cursos online é o fórum de discussão, uma ferramenta assíncrona que permite que os participantes façam reflexões, organizem ideias e expressem pontos de vista.

Dentre as diversas tarefas desenvolvidas pelo SAV, uma delas consiste na avaliação permanente da atividade tutorial na UBA/UFC via Solar. Tal avaliação se dá, entre outras formas, na verificação e classificação das mensagens postadas por cada tutor nos fóruns que são abertos dentro das diversas disciplinas de cada curso oferecido no programa. Estas mensagens podem ser classificadas em quatro categorias distintas: Conteúdo, Dúvidas Respondidas, Explicação de Atividades/Respostas Curtas e Motivação. Historicamente, esta tarefa tem sido feita manualmente e por amostragem, com "avaliadores humanos" selecionando um subconjunto de tutores e de fóruns para então se conectarem ao Solar, lerem as mensagens postadas pelos tutores e anotarem a categoria de cada mensagem postada.

\section{OBJETIVOS}

Podemos definir que o objetivo geral deste trabalho é construir uma investigação científica, baseada nas necessidades pedagógicas do sistema UAB/UFC e nas restrições financeiras e de pessoal impostas a ele, que possa construir elementos de software baseados em ideias e conceitos pedagógicos, estatísticos e computacionais com a finalidade de automatizar tarefas repetitivas e que demandam muito capital humano para que os atores presentes no processo de ensino-aprendizagem possam 
focar seus esforços em atividades mais complexas e gratificantes.

Como objetivos específicos do trabalho em andamentos, podemos listar: 1- Construir um sumário de dados do sistema UAB/UFC que possam ser utilizado em estudos posteriores acerca do processo de avaliação neste sistema; 2 - Construir uma solução de software que possibilite maior inclusão no processo de verificação e classificação de mensagens de tutores em fóruns do Solar.; 3 - Construir modelos que capturem o comportamento dos alunos da UAB/UFC em diferentes momentos.

De forma geral, a ideia central e contribuição do artigo aqui apresentado é a busca pela construção de elementos de automatização que auxiliem o processo de ensinoaprendizagem através da análise profunda do comportamento dos atores envolvidos neste processo. Neste artigo, esta automatização visa conhecer o perfil destes atores, o comportamento discente quanto à sequência de ações feitas dentro do ambiente virtual de aprendizagem e a categorização do retorno textual feito pelos docentes envolvidos via fóruns de comunicação. Assim, esta automatização visa melhorar a atuação dos atores envolvidos, sempre tendo como suporte a atuação humana e possibilitando que aquilo que usualmente é feito via amostragem dentro do sistema UAB/UFC passe a ser feito para todo o conjunto de atores envolvidos, resultando numa desejada melhoria do processo de ensino-aprendizagem.

\section{REFERENCIAL TEÓRICO}

Neste trabalho, foi construído um arcabouço teórico multidisciplinar constituído de elementos de Estatística e Computação que, utilizados em conjunto, deram suporte para o desenvolvimento das diversas ferramentas aqui apresentadas.

Da Estatística resgatamos as ideias de análise exploratória de dados (AE).A análise exploratória tem um potencial muito grande para a síntese dos dados (ASSIS et al., 2016). Essa capacidade facilita a discussão de diversas áreas quanto aos dados encontrados, permitindo uma multidisciplinaridade do conhecimento e expandindo áreas de atuação e alcance da informação que eles trazem.

De um modo geral, pode se dizer que a análise descritiva deve ser um dos primeiros passos em qualquer processo científico, visto que a partir dos resultados dela que se obtém um panorama da situação atual e a partir disso que se pode começar a construir opções quanto ao que fazer em relação a isso.

Da Computação utilizamos elementos de Mineração de Dados (MD) e Redes Neurais 
Artificiais (RNA). Mineração de Dados é uma disciplina em Computação, e também Estatística, focada no processo de extração de informação útil e não-trivial a partir da observação e análise de grandes bases de dados (Han et al., 2011). Para tal, diversas tarefas podem ser efetuados, havendo um padrão industrial e bem definido de passos, o chamado CRISP-DM (Shearer, 2000). Nele, as tarefas são divididas em 6 (seis) grandes passos, e aqui listamos os levados em consideração neste trabalho:

- Entendimento dos Dados: Neste passo busca-se identificar as características principais dos dados que serão objeto de estudo, no caso do projeto corrente, foi listado o conjunto de dados presentes no banco de dados do sistema UAB/UFC e foi construída um dicionário para estes elementos.

- Modelagem: Aqui são construídos e otimizados modelos de diversas naturezas, sejam computacionais, estatísticos, etc, para que se extrai informação a partir do conjunto de dados previamente escolhido. Para tal, decidimos nos utilizar dos modelos de análise exploratória de dados, redes neurais artificiais e séries temporais.

- Avaliação: Dada o entendimento do negócio e os modelos construídos a partir dos dados existentes, é hora de avaliar os resultados obtidos e entender se eles são relevantes para o negócio em questão. No caso do projeto atual, é preciso analisar as implicações de automatizar os processos de avaliação dos atores listados e como o resultado desta automatização ajuda ou atrapalha o desenvolvimento do processo de ensino-aprendizagem.

No passo de modelagem, duas técnicas foram utilizadas inicialmente, sendo uma a arquitetura de RNA's chamada Extreme Learning Machines (ELM) e outra a modelagem estatística de Cadeias de Markov ocultas (HMM).

RNA's são modelos computacionais levemente inspirados pela estrutura biológica das redes de neurônios em cérebros de animais (Rojas, 1996) e que são utilizadas em MD para tarefas de classificação e regressão de dados. Basicamente, RNA's são modelos onde há uma elementos distintos (nós) que são conectados (arestas) entre si de forma bem definida (camadas) onde a camada inicial (entrada) é alimentada por conjuntos de dados, que são transformados através das diversas camadas internas/intermediárias até que na camada final (saída) é apresentado o padrão referente ao conjunto de dados inicialmente apresentado. Tais transformações intermediárias são efetuadas através da escolha das chamadas funções de ativação que modificam os valores recebidos de 
camadas anteriores e retornam uma projeção unidimensional destes valores, que são então passados para a próxima camada.

Dentre as diversas possíveis arquiteturas de redes neurais, uma importante arquitetura é a ELM que é definida como uma rede simplificada com apenas 3 (três) camadas, uma de entrada, uma interna e uma de saída. Tal simplificação possibilita que o modelo seja construído de forma rápida com baixa perda de qualidade nos resultados finais (Huang et. al., 2006).

Como já mencionado, As Cadeias de Markov ocultas (HMM) foram utilizadas para a modelagem. Elas, em especial, são uma forma distinta da Cadeia de Markov comum, que é uma das bases dos Processos Estocásticos (Hillier e Lieberman, 2013).

Processos Estocásticos é o nome dado a área da estatística que estuda a evolução de variáveis aleatórias em um espaço determinístico, usualmente o tempo. As Cadeias de Markov seguem uma estrutura simples em que, cada estado é dependente apenas do estado imediatamente anterior. A partir da observação de um processo que segue uma Cadeia de Markov, é possível se estimar uma matriz de transição que sugere a probabilidade de um estado transitar a outro em qualquer instante de tempo, ou em qualquer espaço de tempo, considerando ou não, os outros estados no meio do percurso.Cadeias de Markov Ocultas, por sua vez, não nos dão os estados em si, mas sim ações provenientes das transições de estado.

\section{PROCEDIMENTOS METODOLÓGICOS}

PARA O OBJETIVO 01: A análise descritiva, geralmente, consiste da aplicação de diversas técnicas para chegar ao seu objetivo. Essas técnicas são as medidas de tendência central (média, mediana e moda), dispersão (desvio padrão e variância), distribuição (curtose) e dependência, caso estejam se tratando a mais de uma variável.

Para realizar a análise, precisamos obter os dados referentes ao período em questão. A partir da obtenção dos dados, podemos calcular os valores de média e desvio padrão para cada variável e formular comparações entre variáveis para estimar se eles possuem algum grau de relação.

Continuando com a ideia, fazemos histogramas dos dados para estabelecer uma visualização do formato e, dependendo da variável em questão, transformamos estes histogramas em boxplots visto que seu formato mais compacto é muito eficiente em estabelecer comparações entre variáveis com escala similar, como no caso de notas de 
avaliação de alunos e tutores.

PARA O OBJETIVO 02: Foi gerado um conjunto anonimizado de mensagens de tutores que foi classificado manualmente pelos avaliadores do SAV e que era referente aos cursos de Administração, Espanhol, Física, Gestão, Matemática, Pedagogia e Português da UAB/UFC. Este conjunto de dados pode ser resumido como:

\begin{tabular}{|c|c|}
\hline Tipo da Mensagem & Quantidade \\
\hline Conteúdo & 243 \\
\hline Dúvidas Respondidas & 111 \\
\hline Explicação de Atividades/Respostas Curtas & 201 \\
\hline Motivação & 270 \\
\hline
\end{tabular}

Seguindo uma linha de pensamento padrão para experimentos desta natureza, foram executados 50 experimentos de treinamento/teste, com uma divisão da base de dados em 80/20 (\%). Além disto, como elemento básico (baseline) para comparação, foi utilizado o método dos Mínimos Quadrados (MQ) (REF) e as redes ELM.

Para a implementação das redes ELM houve uma pequena modificação nos parâmetros da rede, especialmente o número de neurônios da camada intermediária (total de 5 variações).Uma ótima característica deste conjunto de dados é que há um equilíbrio entre a quantidade de mensagens de cada tipo, ou seja, o conjunto de dados está balanceado, uma característica interessante para conjuntos de dados que serão utilizados em um modelo computacional/estatístico (REF). Além disso, os textos foram divididos em um total de 5299 "termos" diferentes, em que foi definido por termo "uma sequência contígua de letras". Por fim, foi necessário decidir a representação que se utilizaria para apresentar tal conjunto de informações ao algoritmo de MD utilizado.

PARA O OBJETIVO 03: A ideia de aplicação de HMM para UAB surgiu de um artigo recente publicado em periódico (Geigle e Zhai, 2017) que tratava da aplicação de uma nova categoria de HMM em camadas para reduzir a evasão de alunos em um MOOC (Massive Open Online Course) famoso. Nele, os pesquisadores relataram um projeto de observar o comportamento dos alunos com base no log de ações realizadas por eles dentro do sistema, e a tentativa de associar determinadas sequências de atividades com o desempenho do aluno, a fim de, com base nisso, criar um modelo comportamental dos estudantes que fosse capaz de prever se um aluno pode evadir do curso. A intenção por trás disso é justamente criar um foco nesses indivíduos que estão com dificuldade e criar soluções para os problemas enfrentados por eles. 


\section{APRESENTAÇÃO E DISCUSSÃO DOS RESULTADOS}

A análise descritiva foi feita para três semestres ao todo: 2015.1, 2015.2 e 2016.1. A amostra contou com 23.796 observações divididas em dez cursos: Português; Inglês; Espanhol; Física; Química; Matemática; Administração; Administração Pública; e Pedagogia. Durante o período analisado, observou-se a nota dada aos tutores pelos alunos e a nota atingida pelos alunos nos cursos. Percebeu-se que os tutores tiveram a grande maioria das notas de avaliação situadas entre 7 e 9 em uma escala de 0 a 10. 0 desempenho dos alunos não foi tão distinto, também ocupando um espaço similar. Entretanto, para eles ainda houve um "pico" na nota zero, indicando provavelmente, uma taxa de evasão dos estudantes. Para facilitar a visualização, nos gráficos abaixo, tem-se na barra 7, por exemplo, todas as notas maiores ou iguais a 7 e menores que 8 .
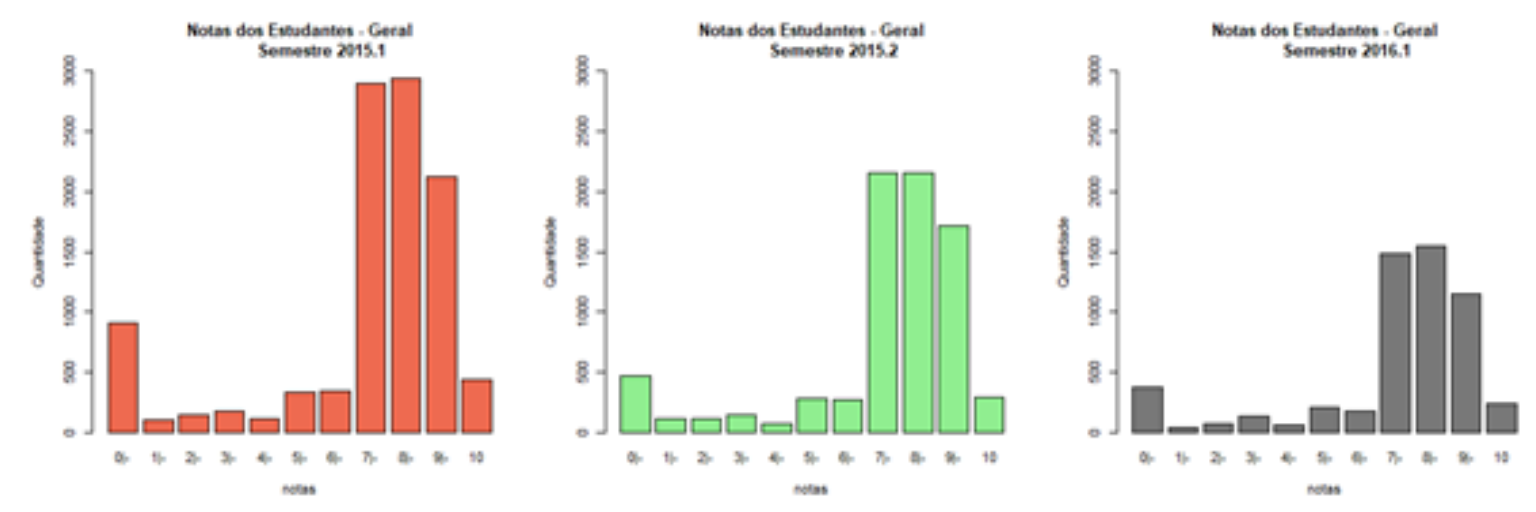

Analisando as notas médias (por turma) dos tutores atribuídas pelos estudantes, percebe-se, assim como nas notas dos estudantes, considerável concentração de ocorrências dentro do intervalo $[7,9]$.
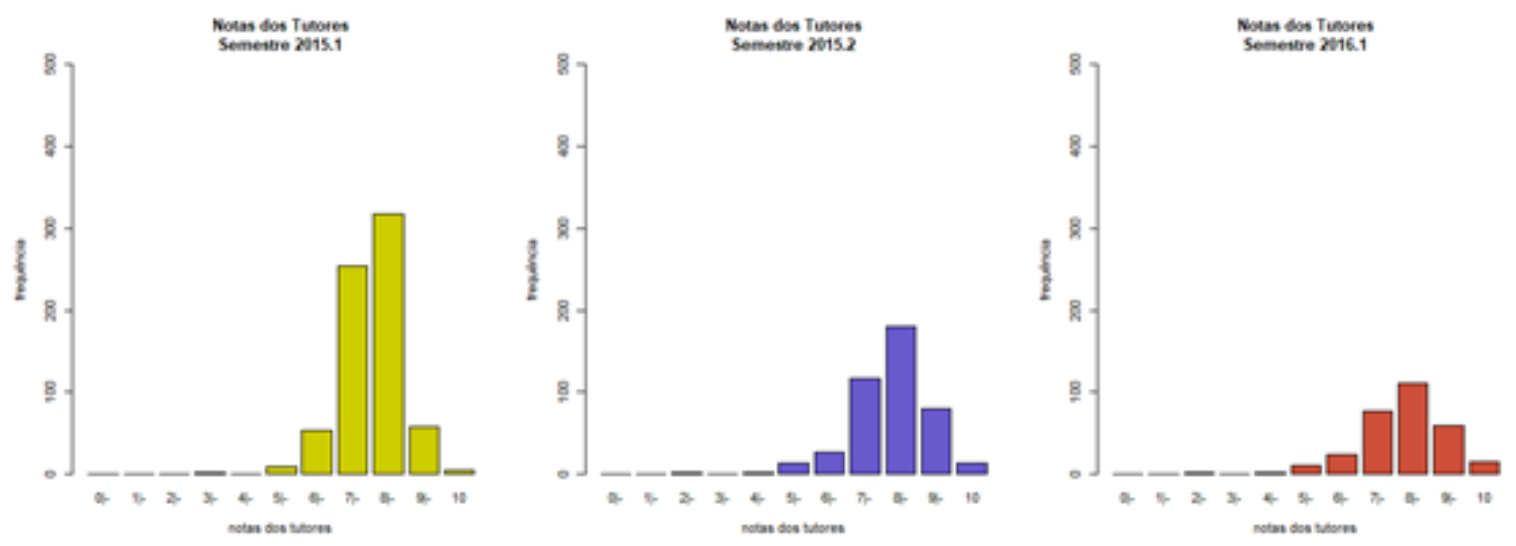

No intuito de encontrar alguma relação entre a nota do professor com a nota do aluno, abordando a situação em que o esforço e dedicação do professor (expresso através de notas altas), tenha influência no bom desempenho dos estudantes (também expresso através de notas altas), foi realizado o agrupamento do banco de dados inicial em dois 
grupos, um com observações nas quais os tutores apresentam nota menor ou igual a 7 e outro com oservações nas quais os tutores apresentam nota maior que 7. No entanto, não foi observada nenhuma correlação considerável entre as notas dos tutores com as notas dos alunos em nenhum dos semestres.
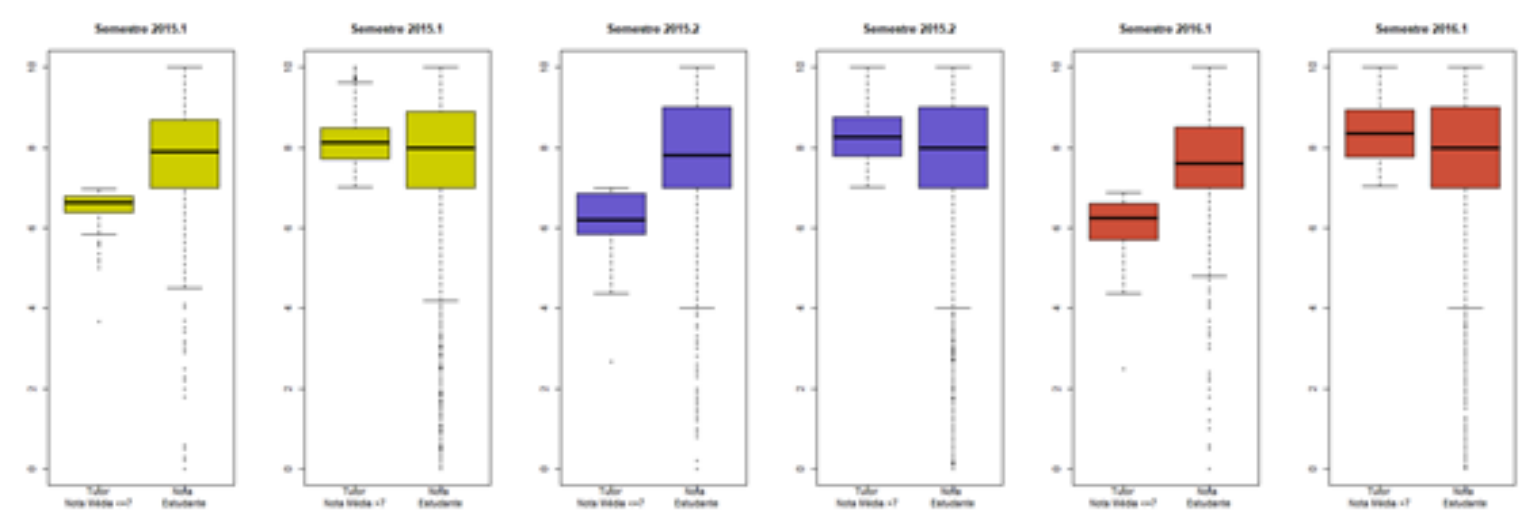

Percebe-se, por exemplo, que no semestre 2015.1, as notas dos estudantes referentes aos tutores que obtiveram nota média menor que 7 , praticamente variaram dentro da mesma amplitude que as notas dos estudantes referentes aos professores que obtiveram nota média maior que 7. Analisando as observações em cada um dos subgrupos definidos considerando todos os semestres juntos, mais uma vez não foi observada correlação entre as notas médias dos tutores com o desempenho dos estudantes. No entanto, ao comparar a nota média das turmas (média das notas dos estudantes por turma) com as notas médias dos tutores, obteve-se os seguintes :
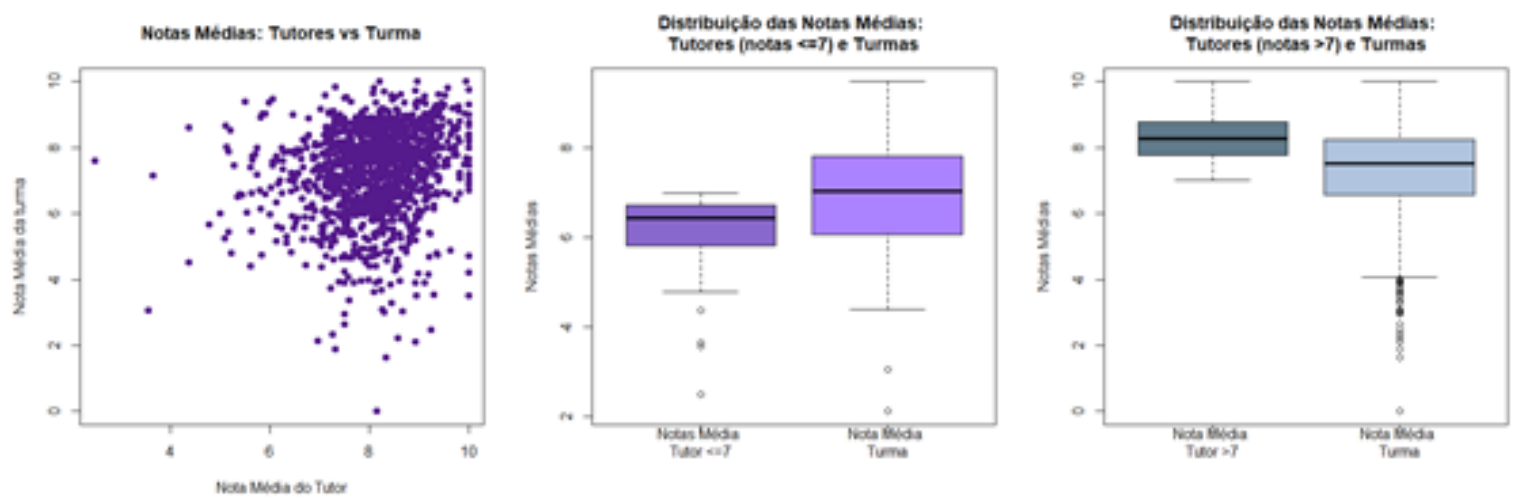

Na primeira destas 3 figuras, observa-se uma grande concentração ocorrência de tutores e turmas com notas médias altas, variando no intervalo [6,10], abrindo espaço para uma possível interpretação em que o bom desempenho dos tutores influenciam no bom desempenho dos estudantes. Tal interpretação é reforçada pelas segunda e terceira figuras da sequência, onde percebe-se que as notas médias das turmas cujo tutores obtiveram notas médias maiores que 7(grupo 1) são menos dispersas que as 
notas médias das turmas cujos os professores com notas médias menores ou iguais que 7 (grupo 2).Apesar da diferença visualmente parecer pouca, o fato das notas médias das turmas do grupo 1 serem menos dispersas que as notas médias das turmas do grupo 2 , aliado ao fato da mediana do grupo 1 ser maior que a mediana do grupo 2, temos indicações o bastante para suspeitar que as notas médias das turmas do grupo 1 tendem a ser maiores que as do grupo 2.

Quanto ao Objetivo 02, a tabela abaixo apresenta as taxas médias de acerto (TMA) e o desvio padrão (DEVPAD) destas taxas, obtidos pelos classificadores utilizados nos experimentos executados (os números entre parênteses expressam a quantidade de neurônios da camada intermediária da rede ELM):

\begin{tabular}{|c|c|c|c|c|c|c|}
\hline & MQ & ELM (5922) & ELM (5972) & ELM (6022) & ELM (6072) & ELM (6122) \\
\hline TMA & 0,2944 & 0,8461 & 0,8478 & 0,8543 & 0,8579 & 0,8591 \\
\hline DEVPAD & 0,0359 & 0,0347 & 0,0308 & 0,0343 & 0,0296 & 0,0332 \\
\hline
\end{tabular}

Tal tabela demonstra dois fatos interessantes. O primeiro é o péssimo desempenho do algoritmo MD, mostrando que uma combinação linear dos atributos apresentados não é suficiente para classificar razoavelmente estas mensagens. O outro é a estabilidade do método ELM, dado que tal método apresenta um baixo desvio-padrão nas taxas de acerto apresentadas. Quando analisadas de forma mais específica, foi percebido que o pior resultado de TMA é apresentado na categoria Dúvidas Respondidas, justamente a classe menos representada no conjunto de treinamento. Tais resultados são apresentados apenas com o conjunto de treinamento, assim não podemos afirmar ainda que as taxas de acerto são boas em um conjunto arbitrário, porém tais resultados nos indicam que o estudo da utilização destes modelos é algo a ser pensado e pode ter uma boa viabilidade. Em relação ao objetivo 03 , o corrente trabalho ainda não possui resultados apresentáveis em virtude do andamento inicial do trabalho.

\section{CONSIDERAÇÕES FINAIS}

Neste trabalho foi investigado o uso de ferramentas computacionais e estatísticas para análise de interações entre tutores e alunos de cursos semipresenciais vinculados à Universidade Aberta do Brasil. Os resultados parciais obtidos indicam que a utlização destas técnicas é produtiva dentro do ambiente de ensino-aprendizagem e, quando postas em produção, podem auxiliar o processo de avaliação dos atores envolvidos. A continuação do trabalho aqui iniciado, a melhora dos modelos apresentados e a colocação dos mesmos como elementos persistentes dentro do AVA são as próximas tarefas a serem colocadas em andamento pelo grupo de pesquisa. 


\section{REFERÊNCIAS}

Assis, J. P. de et al. Estatística descritiva. Piracicaba: FEALQ, 2016. ISBN 9788571330818.

Geigle, C., e Zhai, C..Modeling MOOC Student Behavior With Two-Layer Hidden Markov Models, 2017. Journal of Educational Data Mining, 9(1).

Han, J., Kamber, M. e Pei, J., Data Mining: Concepts and Techniques, The Morgan Kaufmann Series in Data Management Systems.

Hillier, S. F. e Lieberman, G. J.. Introdução à Pesquisa Operacional, 2013. McGraw Hill Brasil, $9^{a}$ edição.

Huang, G-B., Zhu, Q-Y e Siew, C-K, Extreme learning machine: theory and applications, Neurocomputing, 2006. 70 (1): 489-501.

Rojas, R. Neural Networks: A Systematic Introduction, 1996. Springer-Verlag, Berlin, Heidelberg.

Rossato, M., Ramos, M. W., Maciel, D, M. A. 2013. Subjetividade e Interação nos Fóruns Online: Reflexões Sobre a permanência em Educação a Distância. Revista Reflexão e Ação, Santa Cruz do Sul, v.21, n.2, p.399-429, jul./dez.

Santos, P. C., Maciel, D. A. 2014. SIED: Simpósio Internacional de Educação a Distância, EnPED: Encontro de Pesquisadores em Educação a Distância.

Shearer, C., The CRISP-DM Model: The New Blueprint for Data Mining, 2000. Journal of Data Warehousing, 5, 13-22. 